NALEVAIKO, P.C. et al. Leishmaniose no Brasil - Importância e perspectivas. PUBVET, Londrina, V. 5, N. 14, Ed. 161, Art. 1088, 2011.

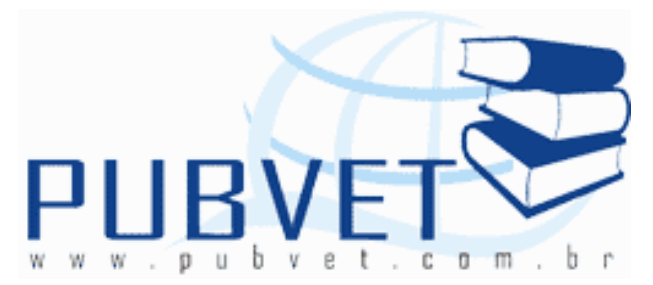

PUBVET, Publicações em Medicina Veterinária e Zootecnia.

\title{
Leishmaniose no Brasil - Importância e perspectivas
}

Priscila Christen Nalevaiko ${ }^{2}$, Roberta Torres de Melo ${ }^{1,2}$, Guilherme Paz

Monteiro², Letícia Ríspoli Coelho ${ }^{1,2}$, Eliane Pereira Mendonça ${ }^{1,2}$, Eduardo Almeida Freitas ${ }^{2}$, Daise Aparecida Rossi ${ }^{1,2}$

${ }^{1}$ Programa de Pós-Graduação em Medicina Veterinária da Universidade Federal de Uberlândia;

${ }^{2}$ Laboratório de Biotecnologia Animal e Aplicada da Universidade Federal de Uberlândia.

\section{Resumo}

A importância atual da leishmaniose no Brasil está diretamente ligada aos aspectos biológicos, ambientais e sociais que favoreceram no processo de expansão e urbanização dos focos da doença. Os métodos atuais de diagnóstico e tratamento ainda não apresentam a especificidade e a sensibilidade desejáveis, já que se trata de uma zoonose de elevado risco. A eficácia e a aplicabilidade desses tratamentos encontram-se ainda em fase de pesquisa. As várias lacunas encontradas, como as medidas de controle e as novas formas de prevenção, podem ser bastante promissoras, mas ainda há muitos desafios a serem superados para o controle desse protozoário no país. 
NALEVAIKO, P.C. et al. Leishmaniose no Brasil - Importância e perspectivas. PUBVET, Londrina, V. 5, N. 14, Ed. 161, Art. 1088, 2011.

\title{
Leishmaniasis in Brazil - Importance and perspective
}

\begin{abstract}
The current importance of leishmaniasis in Brazil is directly linked to biological, environmental and social changes that facilitated the process of expansion and urbanization of the disease. Current methods of diagnosis and treatment have not shown the sensitivity and specificity desirable, since it is a high risk of zoonosis. The effectiveness and applicability of these treatments are still being researched. The number of gaps found in local control measures and new prevention methods, could be very promising, but there are still many challenges to be overcome to control this protozoan in the country.
\end{abstract}

\section{Introdução}

A leishmaniose visceral (LV) é uma zoonose, e vem se tornando um importante problema de Saúde Pública, considerada pela ${ }^{1}$ Organização Mundial da Saúde uma das prioridades dentre as doenças tropicais, devido à sua incidência e alta letalidade. Atualmente, a LV é endêmica em 62 países, com um total estimado de 200 milhões de pessoas sob risco de adquirirem a infecção. Aproximadamente $90 \%$ dos casos ocorrem em 5 países: Índia, Bangladesh, Nepal, Sudão e Brasil ${ }^{2}$. Nas Américas, a LV ocorre desde o México até a Argentina, sendo que cerca de $90 \%$ dos casos humanos descritos são procedentes do Brasil ${ }^{3}$. As leishmanioses são doenças enzoóticas e zoonóticas causadas por protozoários parasitas, morfologicamente similares, do gênero Leishmania (Kinetoplastida: Trypanosomatidae), podendo acometer o homem ${ }^{4}$.

A LV apresentar-se como zoonose, antroponose ou antropozoonose, estas duas últimas, quando o homem atua como reservatório no ciclo de transmissão do parasito ${ }^{5}$. Existe uma grande polêmica em torno da origem da LV no Novo Mundo - se ela foi introduzida recentemente, na época da colonização européia e causada pela espécie $L$. infantum, ou há vários milhões de anos, juntamente com a introdução dos canídeos, devendo a espécie ser 
NALEVAIKO, P.C. et al. Leishmaniose no Brasil - Importância e perspectivas. PUBVET, Londrina, V. 5, N. 14, Ed. 161, Art. 1088, 2011.

classificada como L. chagasi. Os achados de altas taxas de infecção em canídeos originários da Amazônia sugerem a origem autóctone ${ }^{6}$. Entretanto, estudos utilizando técnicas bioquímicas e moleculares consideram a $L$. chagasi e a $L$. infantum uma única espécie e aceitam a hipótese de origem recente nas Américas ${ }^{7}$.

\section{Incidência no Brasil}

No Brasil trata-se de uma zoonose endêmica, que estava inicialmente associada a áreas rurais, mas devido às diversas alterações no ambiente como, desmatamentos, urbanização e intenso processo migratório, ocorreu a expansão das áreas endêmicas, levando à urbanização da doença, principalmente nas regiões Sudeste e Centro Oeste do país. Nos últimos cinco anos, ocorreram em média 3.500 casos humanos novos, sendo a maioria na região Nordeste do país. A partir dos anos 90, os estados Pará e Tocantins (região Norte), Mato Grosso do Sul (região Centro Oeste) e Minas Gerais e São Paulo (região Sudeste) passaram a influir de maneira significativa nas estatísticas da LV no Brasil ${ }^{8}$. Exemplos deste fenômeno de expansãourbanização são surtos epidêmicos em diversos estados do Brasil ${ }^{9} 1011$. Muitos autores já constataram a doença instalada definitivamente em cidades de médio e grande porte, como Teresina, Recife, Rio de Janeiro, Salvador, Belo Horizonte, Montes Claros, Januária, entre outras ${ }^{12}$. Os principais determinantes dos níveis epidêmicos da LV nos grandes centros são: convívio muito próximo homem/reservatório(cão), aumento da densidade do vetor, desmatamento acentuado e o constante processo migratório ${ }^{13}$.

Em estudos realizados no intervalo de 1998 a 2005 no estado de Mato Grosso, a leishmaniose visceral canina foi identificada em 41 municípios, com soropositividade de $9 \%$ em 40.000 cães examinados. Lutzomyia longipalpis e/ou Lutzomyia cruzi foram capturadas em 14 dos 18 municípios que registraram simultaneamente leishmaniose visceral humana e canina. Os resultados indicam que a transmissão da leishmaniose visceral dissemina-se para o interior do estado, acompanhando o fluxo migratório e o processo de 
NALEVAIKO, P.C. et al. Leishmaniose no Brasil - Importância e perspectivas. PUBVET, Londrina, V. 5, N. 14, Ed. 161, Art. 1088, 2011.

ocupação urbana desordenada das cidades $^{14}$. Várzea Grande, município da Região Metropolitana de Cuiabá foi classificado em 2003, pelo Departamento de Vigilância Epidemiológica do Ministério da Saúde, como área de transmissão intensa de LV no Brasil, juntamente com os municípios de Campo Grande e Corumbá, MS, Palmas, TO, Araçatuba, SP, Belo Horizonte e Montes Claros, MG, São Luis, MA e Teresina, $\mathrm{PI}^{15,16}$.

O primeiro relato de LV no Brasil foi feito em 1934, quando foram encontradas amastigotas de Leishmania em cortes histológicos de fígado de pessoas que morreram com suspeita de febre amarela ${ }^{17}$. Somente 20 anos depois é que se registrou o primeiro surto da doença em Sobral, no Ceará ${ }^{18}$. Em meados dos anos 80, constatou-se uma transformação drástica na distribuição geográfica da LV.

No Brasil, a LV clássica acomete pessoas de todas as idades, mas na maior parte das áreas endêmicas $80 \%$ dos casos registrados ocorrem em crianças com menos de 10 anos. Em alguns focos urbanos estudados existe uma tendência de modificação na distribuição dos casos por grupo etário, com ocorrência de altas taxas também no grupo de adultos jovens ${ }^{19}$.

No Brasil, a transmissão de Leishmania chagasi, principal agente etiológico da LV, se dá pela picada de fêmeas de insetos dípteros pertencentes à família Psychodidae, sub-família Phebotominae, conhecidos genericamente por flebotomíneos, tendo como principal vetor Lutzomyia longipalpis. Mais recentemente, Lutzomyia cruzi foi também incriminado como vetor no estado de Mato Grosso do Sul ${ }^{20}$. A espécie L. longipalpis está bem adaptada ao ambiente peridomiciliar, alimentando-se em uma grande variedade de hospedeiros vertebrados, entre aves, homem e outros animais silvestres ou domésticos.

O cão vem sendo apontado como reservatório da doença, e, como hospedeiro doméstico, é, provavelmente, o mais importante reservatório natural relacionado com casos humanos. Esse hospedeiro, apresenta variações no quadro clínico da doença, passando de animais aparentemente sadios a oligossintomáticos podendo chegar a estágios graves da doença, com intenso 
NALEVAIKO, P.C. et al. Leishmaniose no Brasil - Importância e perspectivas. PUBVET, Londrina, V. 5, N. 14, Ed. 161, Art. 1088, 2011.

parasitismo cutâneo ${ }^{21} 22$. Assim, o cão representa uma fonte de infecção para o vetor, sendo um importante elo na transmissão da doença para o homem ${ }^{23}$.

Os hospedeiros silvestres da L. chagasi até agora conhecidos são as raposas e os marsupiais. Duas espécies de raposas foram encontradas naturalmente infectadas: Lycalopex vetulus no Ceará6; e Cerdocyun thous no Pará $^{24}$ e em Minas Gerais ${ }^{25}$. L. chagasi foi isolada em marsupiais do gênero Didelphis na Bahia ${ }^{26}$ e no Rio de Janeiro ${ }^{27}$. O fato destes animais possuírem hábitos sinantrópicos poderia promover a ligação entre os ciclos silvestre e doméstico. No ambiente doméstico, o cão é considerado um importante hospedeiro e fonte de infecção para os vetores, sendo um dos alvos nas estratégias de controle. Entretanto, para se determinar o papel destes animais na manutenção da transmissão da LV, são necessários maiores estudos.

\section{Diagnóstico}

Diferentes técnicas podem ser utilizadas para o diagnóstico de leishmaniose visceral humana e canina. Muitos avanços têm ocorrido nos últimos anos, mas a despeito do grande número de testes disponíveis para o diagnóstico da LV, nenhum apresenta $100 \%$ de sensibilidade e especificidade.

Nos casos humanos, o diagnóstico é rotineiramente realizado com base em parâmetros clínicos e epidemiológicos. Entretanto, um diagnóstico definitivo requer a demonstração do parasita através de métodos parasitológicos, onde a demonstração do parasito pode ser feita em material de biópsia ou punção aspirativa do baço, fígado, medula óssea ou linfonodos. A especificidade destes métodos é de $100 \%$, mas a sensibilidade é muito variável, pois a distribuição dos parasitas não é homogênea no mesmo tecido. A sensibilidade mais alta (98\%) é alcançada quando se utiliza aspirado do baço $^{28}$.

Técnicas sorológicas têm sido utilizadas no diagnóstico da LV humana e canina, porém os testes diferem em sua sensibilidade e especificidade, na sua aplicação prática nas condições de campo e na disponibilidade de reagentes. Os testes têm limitações, podem permanecer positivos durante longo tempo 
NALEVAIKO, P.C. et al. Leishmaniose no Brasil - Importância e perspectivas. PUBVET, Londrina, V. 5, N. 14, Ed. 161, Art. 1088, 2011.

após o tratamento em humanos, não permitindo avaliação do efeito da terapia e podendo ocorrer reações cruzadas com outras doenças. Como há infecções sub-clínicas, um teste positivo necessariamente não indica doença ativa. Os clínicos e os epidemiologistas sempre solicitam exames sorológicos para confirmar o diagnóstico e esperam que os resultados sejam confiáveis, sendo a especificidade e sensibilidade dos testes características essenciais para isto $^{29}$.

Atualmente são usados os testes de aglutinação direta (DAT) tem mostrado em vários estudos sensibilidade de 91 a $100 \%$ e especificidade de 72 a $100 \%$. A técnica combina altos níveis de validade intrínseca e facilidade de execução, embora apresente problemas na padronização e controle de qualidade do antígeno e não tenha valor no prognóstico da doença ${ }^{30}$. Uma variação da DAT, o FAST (Fast Agglutination Screening Test), vem sendo testada para aplicabilidade em situações epidêmicas e para inquéritos populacionais $^{31}$; reação de imunofluorescência indireta (RIFI) apresenta baixa especificidade, exige na sua execução pessoal treinado, é uma reação dispendiosa e não está adaptada para estudos epidemiológicos em larga escala. Uma das principais limitações da técnica é a ocorrência de reações cruzadas com leishmaniose tegumentar, doença de Chagas, malária, esquistossomose e tuberculose pulmonar $^{32}$; e ensaio imunoenzimático (ELISA), que é o mais utilizado para imunodiagnóstico de leishmaniose visceral. É um teste rápido, de fácil execução e leitura, sendo um pouco mais sensível e um pouco menos específico que a RIFI. O teste é sensível, permitindo a deteç̧ão de baixos títulos de anticorpos, mas é pouco preciso na detecção de casos subclínicos ou assintomáticos ${ }^{33}$. Funciona igualmente bem para o diagnóstico da LV canina ${ }^{34}$.

No Brasil, os testes mais utilizados no diagnóstico de LV humana e canina são a RIFI e ELISA, sendo considerados, sobretudo este último, testes de escolha para inquéritos populacionais.

O diagnóstico clínico é complexo, pois a doença no homem pode apresentar sinais e sintomas que são comuns a outras patologias presentes 
NALEVAIKO, P.C. et al. Leishmaniose no Brasil - Importância e perspectivas. PUBVET, Londrina, V. 5, N. 14, Ed. 161, Art. 1088, 2011.

nas áreas onde incide a LV, como, por exemplo, Doença de Chagas, Malária, Esquistossomose, Febre Tifóide e Tuberculose. Pacientes com LV apresentam febre prolongada, esplenomegalia, hepatomegalia, leucopenia, anemia, hipergamaglobulinemia, tosse, dor abdominal, diarréia, perda de peso e caquexia.

O diagnóstico clínico da LV canina é muitas vezes um problema para o veterinário. Há um amplo espectro de sinais clínicos, desde animais aparentemente saudáveis, passando por oligossintomáticos, até estágios severos da doença. Uma característica importante é a permanência da doença clinicamente inaparente por longos períodos. Nos cães, a doença é sistêmica crônica e pode levar o animal à morte. Dependendo da fase da doença e das condições imunológicas, muitos cães infectados se apresentam assintomáticos. Entretanto, já foi demonstrado que cães infectados, mesmo assintomáticos, são fonte de infecção para os flebotomíneos e, conseqüentemente, têm papel ativo na transmissão de Leishmania ${ }^{35}$. Estudos dos fatores de risco para a LV canina no Brasil até o momento não evidenciaram predisposição sexual, racial ou etária relacionada com a infecção. Entretanto, acredita-se que as raças miniaturas sejam menos afetadas por viveram dentro dos domicílios ${ }^{36}$. $\mathrm{Na}$ Europa, há estudos mostrando resultados controversos em relação a estas variáveis ${ }^{37}$.

Novos antígenos estão sendo pesquisados a fim de se conseguir componentes antigênicos purificados que possam ser utilizados como ferramenta para obtenção de um diagnóstico específico, assegurando maior sensibilidade e especificidade aos testes.

Vários antígenos com diferentes massas moleculares têm sido identificados. O antígeno Anti-66KDa mostra especificidade de $100 \%$, mas sensibilidade de apenas $37 \%{ }^{38}$. Um complexo antigênico fucose-manose ligante (FM-ELISA), descrito para o complexo Leishmania donovani foi testado no diagnóstico e prognóstico do calazar humano e canino. $O$ maior componente do antígeno, uma glicoproteina de 36KDa-GP36, produz 100\% de sensibilidade e $96 \%$ de especificidade quando usado no teste de ELISA. Por se 
NALEVAIKO, P.C. et al. Leishmaniose no Brasil - Importância e perspectivas. PUBVET, Londrina, V. 5, N. 14, Ed. 161, Art. 1088, 2011.

tratar de um complexo de glicoproteínas de superfície, o antígeno possui alta estabilidade, o que o torna um bom candidato para trabalhos em larga escala ${ }^{39}$.

Recentemente, um antígeno obtido de promastigotas de L. major-like mostrou $100 \%$ de especificidade e $92 \%$ de sensibilidade para diagnosticar LV humana e canina, sem reações cruzadas com várias doenças incluindo leishmaniose tegumentar ${ }^{40}$.

Um antígeno recombinante bem estudado e já testado no Brasil é o rK39, específico para as espécies do complexo L. donovani. Este antígeno, quando empregado no ELISA, mostrou $100 \%$ de especificidade e $98 \%$ de sensibilidade $^{41}$. Uma importante característica deste antígeno é que ele pode ser empregado em pacientes co-infectados com HIV, nos quais os níveis de anticorpos contra rK39 declinam rapidamente com o sucesso do tratamento ${ }^{42}$.

Um teste imunocromatográfico simples e rápido, baseado na reação do soro ou sangue do paciente, foi desenvolvido utilizando-se o rK39 fixado em papel (Teste Rápido Anticorpo Leishmania donovani - TRALd) ${ }^{43}$. O teste mostrou $100 \%$ de sensibilidade quando aplicado na Índia ${ }^{30}$ e $67 \%$ no Sudão ${ }^{44}$. O TRALd pode apresentar reação cruzada com malária, febre tifóide e tuberculose. No Brasil, quando aplicado em cães de área endêmica, a sensibilidade foi de $92 \%$ e a especificidade de $99,5 \%$. Entretanto, o teste não foi capaz de detectar infecção nos animais com títulos de RIFI baixos de 1:40 até $1: 320^{45}$. Apesar das limitações apresentadas, o teste parece ser promissor para uso em programas de saúde pública, pois requer pequena quantidade de sangue periférico, é de rápida execução e leitura (10 minutos) e pode ser utilizado em condições de campo. Recentemente, o teste foi modificado sendo acrescido do antígeno recombinante rK26 do complexo L. donovani, que também reconhece anticorpos específicos para espécies deste complexo ${ }^{46}$. $\mathrm{Na}$ avaliação do novo TRALd foi observado que indivíduos assintomáticos negativos ao rK39 mostraram-se positivos com o rk26, concluindo-se que o novo TRALd amplia a sensibilidade do teste ${ }^{47}$. 
NALEVAIKO, P.C. et al. Leishmaniose no Brasil - Importância e perspectivas. PUBVET, Londrina, V. 5, N. 14, Ed. 161, Art. 1088, 2011.

Nos testes diagnósticos para LV tem sido utilizado soro de pacientes, enquanto a coleta de sangue em papel filtro tem sido usada em inquéritos populacionais para estudos epidemiológicos ${ }^{48,49}$. Nos inquéritos caninos este é o método de escolha, pois apresenta as vantagens de ser de coleta simples e fácil armazenamento, além de poder ser usado em larga escala.

Alguns métodos para a detecção de antígenos na urina de pacientes com LV de diferentes áreas geográficas apresentaram bons resultados, mas a detecção de casos assintomáticos não foi confirmada ${ }^{50}$. Uma das vantagens apresentadas é que os antígenos não foram detectados depois da terceira semana de tratamento, sugerindo um bom valor prognóstico ${ }^{51}$. Entretanto, não existe ainda um sistema disponível com comprovada aplicabilidade.

Métodos de hibridização com sondas específicas e técnicas de amplificação de ácidos nucléicos, incluindo a reação em cadeia da polimerase transcriptase reversa (RT-PCR) para detecção de RNA e PCR para deteç̧ão de DNA, estão disponíveis para identificação do parasita. Diferentes tipos de amostras biológicas, tais como aspirados esplênicos, de medula óssea, de linfonodos, sangue total, camada leucocitária, cultura e sangue coletado em papel-filtro, podem ser utilizados como fonte de material para as reações ${ }^{52}$.

A hibridização do DNA foi o primeiro método de biologia molecular desenvolvido para diagnóstico. Sua especificidade é alta, mas sua sensibilidade é baixa ${ }^{53}$. Vários sistemas baseados em PCR têm sido desenvolvidos para Leishmania ${ }^{54}$. O melhor alvo para PCR e para as sondas de DNA tem sido o DNA presente nos minicírculos do KDNA da região conservada ou a amplificação do minicírculo completo.

A técnica de PCR tem sido utilizada com várias finalidades além do diagnóstico, tais como o monitoramento do tratamento e estudos epidemiológicos. Esta técnica tem sido descrita como um método sensível para a deteç̧ão do parasita, independente da imunocompetência ou da história clínica do paciente ${ }^{55}$. Muitos centros de pesquisas têm avaliado o uso da PCR para o diagnóstico de LV utilizando o sangue periférico, considerando que a biópsia esplênica e a punção de medula óssea não são técnicas adequadas 
NALEVAIKO, P.C. et al. Leishmaniose no Brasil - Importância e perspectivas. PUBVET, Londrina, V. 5, N. 14, Ed. 161, Art. 1088, 2011.

para uso fora do ambiente hospitalar ${ }^{55}$. Apesar de ser um método sensível para a deteç̧ão de Leishmania em uma variedade de materiais clínicos de humanos e cães, a PCR é mais usada em estudos epidemiológicos do que no diagnóstico de rotina ${ }^{56}$. Para utilização em larga escala, a PCR necessita de ajustes para se tornar mais simples e com custo operacional mais baixo.

$\mathrm{Na}$ era pós-genômica há um número crescente de seqüências de nucleotídeos de DNA de Leishmania, obtidos não só no projeto genoma, mas também de trabalhos individuais. Esses dados podem ser utilizados para estudar a função de diversos genes, podendo esclarecer aspectos da relação hospedeiro/parasita e eventualmente ser utilizados como instrumento de diagnóstico e ainda indicar possíveis alvos quimioterápicos.

\section{Tratamento}

Por mais de sessenta anos, o tratamento das leishmanioses vem sendo realizado com antimoniais pentavalentes: antimoniato de $\mathrm{N}$-metil glucaminaGlucantime $^{\circledR}$ e estibogluconato de sódio-Pentostan ${ }^{\circledR}$, que são os medicamentos de primeira escolha para o tratamento. Estas drogas são tóxicas, nem sempre efetivas, e na LV são usadas em esquemas prolongados.

O principal efeito colateral do glucantime é sua ação sobre o aparelho cardiovascular, sendo desaconselhável sua utilização durante os dois primeiros trimestres de gravidez. Como tratamentos alternativos no Brasil, são utilizadas a anfotericina B e suas formulações lipossomais (anfotericina B - lipossomal e anfotericina B - dispersão coloidal), as pentamidinas (sulafto e mesilato) e os imunomoduladores ( interferon gama e GM-CSF). Com exceção das duas primeiras drogas, as demais se encontram ainda em fase de investigação. A utilização destas drogas só deve ser realizada em hospitais de referência ${ }^{57}$. Dados recentes indicam que a resistência aos antimoniais tem se tornado um problema na Índia e no Sudão. No entanto, a quimioterapia das leishmanioses está mais promissora atualmente do que há alguns anos, com novas drogas e novas formulações para as drogas que já vinham sendo utilizadas ${ }^{58}$. O desenvolvimento de anfotericina B encapsulada em lipossomas (AmBisome) 
NALEVAIKO, P.C. et al. Leishmaniose no Brasil - Importância e perspectivas. PUBVET, Londrina, V. 5, N. 14, Ed. 161, Art. 1088, 2011.

tem mostrado bons resultados, com cura de 90-95\% na Índia. O miltefosine, uma droga desenvolvida como um agente antitumoral, mostrou 95\% de cura efetiva em estudo no calazar indiano. Esta droga apresenta a vantagem de ser de uso oral e bem tolerada, embora seja potencialmente teratogênica, o que limita a sua utilização por grávidas e nutrizes ${ }^{59}$. As novas drogas, principalmente AmBisome e miltefosine, têm mudado o perfil do tratamento da LV, mas o custo das novas terapias leva a diferentes práticas de tratamento, de acordo com a condição socioeconômica e cultural de cada região ${ }^{60}$.

\section{Perspectiva atual}

O Brasil enfrenta atualmente a expansão e urbanização da LV com casos humanos e grande número de cães positivos em várias cidades de grande e médio porte. O ciclo de transmissão, que anteriormente ocorria no ambiente silvestre e rural, hoje também se desenvolve em centros urbanos. Duas décadas após o registro da primeira epidemia urbana em Teresina, no Piauí ${ }^{61}$, o processo de urbanização se intensificou com a ocorrência de importantes epidemias em várias cidades da região Nordeste (São Luís, Natal e Aracaju), Norte (Boa Vista e Santarém), Sudeste (Belo Horizonte e Montes Claros) e Centro Oeste (Cuiabá e Campo Grande) ${ }^{62}$.

Belo Horizonte, capital do estado de Minas Gerais, ilustra claramente o processo de urbanização da LV nas cidades brasileiras. Desde 1993, a cidade convive com a leishmaniose visceral, introduzida a partir de um município vizinho. Pelo fato da urbanização ser um fenômeno relativamente novo, pouco se conhece sobre a epidemiologia da LV nos focos urbanos. As relações entre os componentes da cadeia de transmissão no cenário urbano parecem ser bem mais complexas e variadas do que no rural.

De acordo com a Portaria GM/MS No. 2.472 de 31 de agosto de 2010, todo caso de LTA é de notificação obrigatória às autoridades locais de saúde. Deve-se realizar a investigação epidemiológica em até 48 horas após a notificação, avaliando a necessidade de adoção de medidas de controle pertinentes" 63 . Mesmo assim os dados disponíveis são baseados na detecção 
NALEVAIKO, P.C. et al. Leishmaniose no Brasil - Importância e perspectivas. PUBVET, Londrina, V. 5, N. 14, Ed. 161, Art. 1088, 2011.

passiva de casos. O número de pessoas expostas à infecção ou infectadas sem sintomas é em algumas áreas muito maior do que o número de casos detectado $^{49}$. A ocorrência nas áreas urbanas de infecções subclínicas decorrentes da permanente exposição do homem às picadas infectantes prenuncia um grave problema associado à circulação do vírus HIV, podendo transformar a LV em parasitose oportunista ${ }^{50}$. Realmente, a LV apresenta comportamento diferente na co-infecção com HIV, que se reflete principalmente na resposta irregular ao tratamento e alteração do padrão diagnóstico. Tem sido constatado o crescente número de casos de co-infecção Leishmania/HIV em áreas urbanas do Brasil, levando ao aparecimento de nova forma de transmissão pelo compartilhamento de agulhas contaminadas, com risco de instalação do ciclo antroponótico artificial ${ }^{62}$.

O processo de expansão geográfica e urbanização da LV conduzem à necessidade de se estabelecer medidas mais eficazes de controle. Na maior parte dos estudos sobre epidemias urbanas tem sido relatado o encontro de cães infectados ${ }^{64}$, e em algumas áreas foi possível observar que a LV canina precedeu o aparecimento da doença humana ${ }^{51}$. Entretanto, há questionamentos sobre se a LV canina é realmente um fator de risco para a LV humana. Não há concordância entre os pesquisadores de que a LV canina seja causa necessária para a LV humana, embora a maioria dos estudos até agora realizados apontem nessa direção. Esta é uma questão que necessita de maiores estudos para ser inteiramente esclarecida.

O início do programa de controle no Brasil remonta à década de 50 e tinha como objetivo quebrar os elos epidemiológicos da cadeia de transmissão da doença. Entretanto, diante da falta de evidências de que as medidas até então empregadas conduziam a um impacto positivo na redução da incidência da doença humana no país, o Ministério da Saúde/FUNASA convocou em 2000 um comitê de especialistas para, juntamente com a Gerência do Programa, reavaliar as estratégias de controle empregadas e redirecionar as ações de controle visando a racionalização da atuação ${ }^{65}$. Este aprimoramento vem sendo realizado com base em evidências encontradas na literatura científica e 
NALEVAIKO, P.C. et al. Leishmaniose no Brasil - Importância e perspectivas. PUBVET, Londrina, V. 5, N. 14, Ed. 161, Art. 1088, 2011.

de ordem operacional, dentre elas: falta de padronização dos métodos de diagnóstico da infecção humana e canina; discordância entre os estudos que avaliam o impacto da eliminação de cães soropositivos na prevalência da infecção humana; demonstração de que outros reservatórios podem ser fonte de infecção da L. chagasi, como os canídeos silvestres e os marsupiais; escassez de estudos sobre o impacto das ações de controle dirigidas contra os vetores.

Um programa de controle foi proposto para ser aplicado nas áreas consideradas de risco, aglomerados urbanos ou rurais, onde critérios epidemiológicos, ambientais e sociais servirão de base para a delimitação da área a ser trabalhada, tendo como indicador a ocorrência de casos humanos. O controle integrado dará ênfase à atenção ao homem, com capacitação de pessoal técnico e profissionais de saúde para diagnóstico e tratamento, lembrando que as demais medidas de controle devem estar sempre integradas para que possam ser efetivas. A vigilância epidemiológica é um dos componentes do Programa de Controle da Leishmaniose Visceral (PCLV) que visa reduzir as taxas de letalidade e o grau de morbidade através do diagnóstico e tratamento precoce dos casos humanos, bem como da diminuição dos riscos de transmissão mediante controle da população de reservatórios e vetores. O novo enfoque do PCLV incorpora áreas sem ocorrência de casos humanos ou caninos da doença nas ações de vigilância e controle, objetivando evitar ou minimizar a expansão da doença ${ }^{57}$.

Teoricamente, as estratégias de controle parecem adequadas, mas na prática a prevenção de doenças transmissíveis por vetores biológicos é bastante difícil, ainda mais quando associada à existência de reservatórios domésticos e silvestres e aos aspectos ambientais, incluindo aspectos físicos de utilização do espaço habitado.

O entendimento das interações entre mudanças do meio ambiente urbano e os flebotomíneos vetores constituem um pré-requisito para o desenvolvimento de ações apropriadas de prevenção e estratégias de controle. Um dos fatores de risco mais importantes na aquisição da LV é a exposição ao 
NALEVAIKO, P.C. et al. Leishmaniose no Brasil - Importância e perspectivas. PUBVET, Londrina, V. 5, N. 14, Ed. 161, Art. 1088, 2011.

inseto vetor. Lutzomyia longipalpis é uma espécie que se perpetua em diferentes biótopos e nenhuma outra espécie de flebotomíneo do Novo Mundo é tão sinantrópica ${ }^{66}$. O controle do vetor tem sido baseado no uso de inseticida direcionado para as formas adultas, uma vez que os criadouros da espécie são pouco conhecidos.

Com ação residual o inseticida é aplicado no interior das casas e abrigos de animais, medida esta considerada eficaz para reduzir a população de flebotomíneos, como também os níveis de transmissão ${ }^{67}$. Também foram tentadas experiências baseadas no controle do vetor e centradas no reservatório canino, como os experimentos recentes com coleiras impregnadas com deltametrina, que têm mostrado resultados promissores na proteção dos animais, com conseqüências na transmissão ${ }^{68}$.

O impacto do controle canino através da remoção e sacrifício dos cães soropositivos tem sido discutido por se mostrar trabalhoso e de eficácia duvidosa ${ }^{69}$.

A realização de inquéritos sorológicos caninos (amostrais ou censitários), além de sua função de controle do reservatório canino em extensas áreas, tem papel fundamental na deteç̧ão de focos silenciosos da doença e na delimitação de regiões ou setores de maior prevalência, onde a execução das medidas de controle se faz mais necessária.

Tendo em vista que os métodos até agora utilizados têm sido somente parcialmente efetivos na prevenção e controle da doença, novas estratégias de controle devem ser desenvolvidas. A prevenção da doença nos cães através da imunoprofilaxia aparece como uma das poucas alternativas para o controle. Além disso, não existe tratamento eficaz ou profilático para o cão infectado ${ }^{70}$.

As perspectivas para vacinas contra LV humana e canina foram recentemente revistas $^{71}$. Não há até o presente uma vacina humana eficaz, e as duas vacinas já descritas na literatura para cães não mostraram eficácia no campo.

Uma nova vacina desenvolvida na Universidade Federal do Rio de Janeiro, e já testada em campo, foi capaz de proteger $92-95 \%$ dos cães 
NALEVAIKO, P.C. et al. Leishmaniose no Brasil - Importância e perspectivas. PUBVET, Londrina, V. 5, N. 14, Ed. 161, Art. 1088, 2011.

vacinados contra $\mathrm{LV}^{72}$. Considerada uma vacina de segunda geração, a vacina FML, com o aval do Ministério da Agricultura, Pecuária e Abastecimento, está sendo industrializada e comercializada com o nome de Leishmune, pela Fort Dodge ${ }^{\circ}$ Saúde Animal a partir de 2004. Mas o Ministério da Saúde não autoriza a utilização desta vacina como medida de controle da leishmaniose visceral no Brasil, por entender que os estudos até agora realizados referemse à eficácia vacinal canina, e por não ter sido ainda realizado estudo com relação ao impacto na incidência humana e canina, assim como estudos de custo/efetividade e custo/benefício ${ }^{73}$.

A Fundação Nacional de Saúde e Sociedade Brasileira de Medicina Tropical, em conjunto com várias universidades estão trabalhando a fim de entender melhor a complexidade do problema, através de seminários e trabalhos científicos, onde durante esses encontros, os órgãos operacionais e a comunidade científica identificam as dificuldades técnicas e operacionais, discutem as estratégias de intervenção e tentam definir as áreas prioritárias de pesquisa. De fato há que se valorizar e incentivar novas investigações e pesquisas aplicadas como fontes importantes de informações para subsidiar o Programa de Controle da LV no Brasil.

\section{Considerações Finais}

Em virtude das características epidemiológicas da leishmaniose, as estratégias de controle devem ser flexíveis, distintas e adequadas a cada região ou foco em particular. A diversidade de agentes, de reservatórios, de vetores e a situação epidemiológica dessa zoonose, aliada ao conhecimento ainda insuficiente sobre vários aspectos, evidenciam a complexidade do controle desta endemia. 
NALEVAIKO, P.C. et al. Leishmaniose no Brasil - Importância e perspectivas. PUBVET, Londrina, V. 5, N. 14, Ed. 161, Art. 1088, 2011.

\section{Referências}

1. Lainson R, Shaw JJ. Evolution, classification and geographical distribution. In: Peters W, Killick-Kendrick R (eds) The Leishmaniasis in Biology and Medicine, Academic Press Inc, London, p. 1-120, 1987.

2. World Health Organization. The world health report 2001. Geneva; 2001

3. Grimaldi JG, Tesh RB, McMahon-Pratt D. A review of geographical distribution and epidemiology of leishmaniasis in the New World. The American Journal Tropical Medicine Hygiene 41: 687-725, 1989.

4. Chance ML. The biochemical and immunotaxonomy of Leishmania. In: Chang/Gray (eds) Elsevier Science Publishing Company, USA, p. 93-110, 1985.

5. Passos VMA, Falcão AL, Marzochi MCA, Gontijo CMF, Dias ES, Barbosa-Santos EGO, Guerra $\mathrm{HL}$, Katz N. Epidemiological aspects of american cutaneous leishmaniasis in a periurban area of the metropolitan region of Belo Horizonte, Minas Gerais, Brazil. Memórias do Instituto Oswaldo Cruz 88(1): 103-110, 1993.

6. Lainson R, Shaw JJ, Silveira FT, Braga RR. American visceral leishmaniasis: on the origin of Leishmania (Leishmania) chagasi. Trans R Soc Trop Med Hyg 1987; 81: 517.

7. Mauricio IL, Stohard JR, Miles MA. The strange case of Leishmania chagasi. Parasitol Today $2000 ; 16: 188-9$.

8. Ministério da Saúde. Fundação Nacional de Saúde.Centro Nacional de Epidemiologia. Leishmaniose Visceral no Brasil: situação atual, principais aspectos epidemiológicos, clínicos e medidas de controle. Boletim Epidemiológico 2001; 6: 1-11.

9. Cunha S, Freire M, Eulalio C, Cristóvao J, Netto E, Johnson WD, Reed SG, Badaro R. Visceral leishmaniasis in a new ecological niche near a major metropolitan area of Brazil. Transactions of the Royal Society of Tropical Medicine and Hygiene 89: 155-158, 1995.

10. Marzochi MCA, Marzochi KBF. Tegumentary and visceral leishmaniasis in Brazil. Emerging anthropozoonosis and possibilities for their control. Cadernos de Saúde Pública 10: 359-375, 1994.

11. Monteiro SP, Lacerda MM, Arias JR. Controle da leishmaniose visceral no Brasil. Revista da Sociedade Brasileira de Medicina Tropical 27: 67-72, 1994.

12. Deane LM. Leishmaniose Visceral no Brasil. Estudos sobre reservatórios e transmissores no Estado do Ceará. Tese, Faculdade de Medicina da Universidade de São Paulo, Rio de Janeiro, RJ, 1956.

13. Marzochi MCA. A leishmaniose tegumentar no Brasil. In: Grandes Endemias Brasileiras. Universidade de Brasília, Brasília.1989.

14. Evans TG, Vasconcelos IAB, Lima JW, Teixeira JM, Macrullife IT, Lopes UG, Pearson RD, Vasconcelos AW. Canine visceral leishmaniasis in northeast Brazil: Assessment of serodiagnosis methods. American Journal of Tropical Medicine and Hygiene 42: 118-123, 1990 
NALEVAIKO, P.C. et al. Leishmaniose no Brasil - Importância e perspectivas. PUBVET, Londrina, V. 5, N. 14, Ed. 161, Art. 1088, 2011.

15. Camargo-Neves VLF, Katz G, Rodas LAC, Poletto DW, Lage LC, Spínola RMF, Cruz OG. Utilização de ferramentas de análise espacial na vigilância epidemiológica de leishmaniose visceral americana - Araçatuba, São Paulo, Brasil, 1998-1999. Cadernos de Saúde Pública 17: 1263-1267, 2001.

16. Monteiro EM, França-Silva JC, Costa RT, Costa DC, Barata RA, Paula EV, Machado-Coelho GLL, Rocha MF, Fortes-Dias CL, Dias ES. Leishmaniose visceral: Estudo de flebotomíneos e infecção canina em Montes Claros, Minas Gerais. Revista da Sociedade Brasileira de Medicina Tropical 38: 147-152, 2005.

17. Penna HA. Leishmaniose visceral no Brasil. Bras Méd 1934; 48: 949-50.

18. Deane LM. Leishmaniose Visceral no Brasil. Serviço Nacional de Educação Sanitária. Rio de Janeiro; 1956.

19. Silva ES, Gontijo CMF, Pacheco RS, Fiuza VOP, Brazil RP. Visceral Leishmaniasis in the Metropolitan Region of Belo Horizonte, State of Minas Gerais, Brazil. Mem Inst Oswaldo Cruz 2001; 3: 285-91.

20. Gallati EAB, Nunes VLB, Rêgo Jr. FA, Oshiro ET, Chang MR. Estudo de Flebotomíneos (Diptera:Psychodidae) em foco de leishmaniose visceral no Estado de Mato Grosso do Sul, Brasil. Revista de Saúde Pública 31: 378-390,1997.

21. Costa CHN, Pereira HF, Pereira FCA, Tavares JP, Gonsalves MJO. Is the household dog a risk factor for American visceral leishmaniasis in Brazil? Transactions of the Royal Society of Tropical Medicine and Hygiene 93: 464, 1999.

22. Deane LM, Deane MP. Leishmaniose visceral urbana (no cão e no homem) em Sobral, Ceará. O Hospital 47: 75-87, 1955.

23. Deplazes $P$, Smith NC, Arnold P, Lutz H, Eckert J. Specific IgG1 and IgG2 antibody responses of dogs to Leishmania infantum and other parasites. Parasite Immunology 17: 451458, 1995.

24. Lainson R, Dye C, Shaw JJ, Macdonald DW, Courtenay O, Souza AA et al. Amazonian visceral leishmaniasis - Distribution of the vector Lutzomyia longipalpis (Lutz and Neiva) in relation to the fox Cerdocyon thous (Linn.) and the efficiency of this reservoir host as a source of infection. Mem Inst Oswaldo Cruz 1990; 85: 135-7.

25. Silva ES, Pirmez C, Gontijo CMF, Fernandes O, Brazil RP. Visceral leishmaniasis in a crabeating fox (Cerdocyon thous) in south-east Brazil. Vet Rec 2000; 147: 421-2

26. Sherlock IA, Miranda JC, Sadigursky M, Grimaldi Jr G. Natural infection of the opossum Didelphis albiventris (Marsupialia: Didelphidae) with Leishmania donovani in Brazil. Mem Inst Oswaldo Cruz 1984; 79: 511.

27. Sherlock IA, Miranda JC, Sadigursky M, Grimaldi Jr G. Natural infection of the opossum Didelphis albiventris (Marsupialia: Didelphidae) with Leishmania donovani in Brazil. Mem Inst Oswaldo Cruz 1984; 79: 511.

28. Sundar S, Rai M. Laboratory diagnosis of visceral Leishmaniasis. Clin Diagn Lab Immunol 2002; 9: 951-8. 
NALEVAIKO, P.C. et al. Leishmaniose no Brasil - Importância e perspectivas. PUBVET, Londrina, V. 5, N. 14, Ed. 161, Art. 1088, 2011.

29. Gontijo C.M. F., Melo M.N. Visceral Leishmaniasis in Brazil: current status, challenges and prospects. Rev. bras. epidemiol. vol.7 no.3 São Paulo Sept. 2004

30. Boelaert M, El Safi S, Mousa H, Githure J, Mbati P, Gurubacharya V et al. Multicenter evaluation of repeatability and reproducibility of the direct agglutination test for visceral leishmaniasis. Trop Med Int Health 1999; 4: 31-7.

31. Schoone GJ, Hailu A, Kroon CC, Nieuenhuys JL, Schalling HDFH, Oskam L. A fast agglutination screening test (FAST) for detection of anti-Leishmania antibodies. Trans $R S$ Trop Med Hyg 2001; 95: 400-1.

32. Sundar S, Rai M. Laboratory diagnosis of visceral Leishmaniasis. Clin Diagn Lab Immunol 2002; 9: 951-8.

33. El-Amin ER, Wright EP, Abdel Rahman AM, Kolka A, Laarman JJ, Pondman KW. Serodiagnosis of Sudanese visceral and mucosal leishmaniasis: comparison of ELISAimmunofluorescence and indirect haemagglutination. Trans R Soc Trop Med Hyg 1986; 80: 271-4.

34. Evans TG, Vasconcelos IAB, Lima JB, Teixeira MJ, McAuliffe IT, Lopes UG et al. Canine visceral leishmaniasis in northeast Brazil: assessment of serodiagnosis methods. Am J Trop Med Hyg 1990; 42: 118-23.

35. . Palatnick de Souza CB, Santos WR, França-Silva JC, da Costa RT, Barbosa Reis A, Palatnick $M$ et al. Impact of canine control on the epidemiology of canine and human visceral leishmaniasis in Brazil. Am J Trop Med Hyg 2001; 65: 510-7.

36. Guerin PJ, Olliaro P, Sundar S, Boelaert M, Croft SL, Desjeux $P$ et al. Visceral leishmaniasis: current status of control, diagnosis and treatment and a proposed research and development agenda. Lancet Infect Dis 2002; 2: 494-501.

37. Kar K. Serodiagnosis of Leishmaniasis. Crit Rev Microb 1995; 21: 123-52.

38. Vinayak VK, Mahajan D, Sobti RC, Singla N, Sundar S. Anti-66kDa anti-leishmanial antibodies as specific immunodiagnosis probe for visceral leishmaniasis. Indian J Med Res 1994; 99: 109-14.

39. Weiss JB. DNA probes and PCR for diagnosis of parasitic infections. Clin Microbiol Rev 1995; 8: 113-30.

40. Barbosa de Deus R, Mares Guia ML, Nunes AZ, Costa KM, Junqueira RG, Mayrink W et al. Leishmania major-like antigen for specific and sensitive serodiagnosis of human and canine visceral leishmaniasis. Clin Diagn Lab Immunol 2002; 9: 1361-6.

41. Burns JM Jr, Shreffler WG, Benson DR, Ghalib HW, Badaró R, Reed S. Molecular characterization of a kinesin-related antigen of Leishmania chagasi that detects specific antibody in African and American visceral leishmaniasis. Proc Natl Acad Sci 1993; 90: 775-9.

42. Houghton RL, Petrescu M, Benson DR, Skeiky YA, Scalone A, Badaró R et al. A cloned (recombinant K39) of Leishmania chagasi diagnostic for visceral leishmaniasis in human immunodeficiency virus type 1 patients and a prognostic indicador for monitoring patients undergoing drug therapy. J Infect Dis 1998; 177: 1339-44. 
NALEVAIKO, P.C. et al. Leishmaniose no Brasil - Importância e perspectivas. PUBVET, Londrina, V. 5, N. 14, Ed. 161, Art. 1088, 2011.

43. Reed SG, Shreffler WG, Burns JM, Scott JM, Orge MG, Ghalib HW et al. An improved serodiagnostic procedure for visceral leishmaniasis. Am J Trop Med Hyg 1990; 43: 632-9.

44. Zijlstra EE, Nur Y, Desjeux P, Khalii EA, El-Hassan AM, Groen J. Diagnosing visceral leishmaniasis with the recombinant k39 strip test: experience from the Sudan. Trop Med Int Health 2001; 6: 108-13.

45. Genaro O, Costa RT, França Silva JC, Reis AB, Vieira EP, Arias JR et al. Evaluation of an immunochromatographic assay for the diagnosis for dogs experimentally and naturally infected with Leishmania chagasi in Brazil. Acta Parasitol Turcica 1997; 21 Supplemment 1: 93.

46. Tavares CAP, Fernandes AP, Melo MN. Molecular diagnosis of Leishmaniasis. Expert Rev Mol Diagn 2003; 3: 657-67.

47. Nakatani M, Miranda-Badaró R, Meireles A, Trigo J, Netto EM, Badaró R. Avaliação da sensibilidade do teste rápido (TRALd) para detecção de anticorpos anti-Leishmania com o novo antígeno k26 adicionado ao k39. Rev Bras Med Trop 2001; Suplemento: 10.

48. Ibraim ME, Lambson B, Yousif AAO, Deifalla NS, Alnaiem DA, Ismail A et al. Kala-azar in a high transmission focus: an ethnic and geographic dimension. Am J Trop Med Hyg 1999; 61: 941-4.

49. Moreno E, Melo MN, Antunes CMF, Lambertucci JR, Serufo JC, Andrade-Ribeiro AS et al. Epidemiologia da Leishmaniose Visceral Humana assintomática em área urbana, Sabará, Minas Gerais, 1998-1999. Informe Epidemiólogico do SUS 2002; 11: 37-9.

50. Attar ZJ, Chance ML, El-Safi S, Carney J, Azazy A, El-Hadi M et al. Latex agglutination test for the detection of urinary antigens in visceral leishmaniasis. Acta Tropica 2001; 78: 11-6.

51. Tavares CAP, Fernandes AP, Melo MN. Molecular diagnosis of Leishmaniasis. Expert Rev Mol Diagn 2003; 3: 657-67.

52. Tavares CAP, Fernandes AP, Melo MN. Molecular diagnosis of Leishmaniasis. Expert Rev Mol Diagn 2003; 3: 657-67.

53. Weiss JB. DNA probes and PCR for diagnosis of parasitic infections. Clin Microbiol Rev 1995; 8: 113-30.

54. Schalling HDFH and Oskan L. Molecular biological applications in the diagnosis and control of leishmaniasis as parasite identification. Trop Med Int Health 2002; 7: 641-51.

55. Lachaud L, Chabbert E, Dubessay P, Reynes J, Lamothe J, bastien P. Comparison of various sample preparation methods for PCR diagnosis of visceral leishmaniasis using peripheral blood. J Clin Microbiol 2001; 39: 613-7.

56. Solano-Gallego L, Morell P, Arboix M, Alberola J, Ferrer L. Prevalence of Leishmania infantum infection in dogs living in an area of canine leishmaniasis endemicity using PCR on several tissues and sorology. J Clin Microbiol 2001; 39: 560-3.

57. Ministério da Saúde do Brasil. Secretaria de Vigilância em Saúde. Departamento de Vigilância Epidemiológica. Manual de Vigilância e Controle da Leishmaniose Visceral. Série A. Normas e Manuais Técnicos. Brasília, DF; 2003. 
NALEVAIKO, P.C. et al. Leishmaniose no Brasil - Importância e perspectivas. PUBVET, Londrina, V. 5, N. 14, Ed. 161, Art. 1088, 2011.

58. Croft SL, Yardley V, Kendrick H. Drug sensitive of Leishmania species: some unresolved problems. Trans R Soc Trop Med Hyg 2002; S1: 127-9.

59. Prasad R, Kumar R, Jaiswal BP, Singh UK. Miltefosine: An oral drug for Visceral Leishmaniasis. Indian J Pediatr 2004; 71: 143-4.

60. Marty P, Rosenthal E. Treatment of visceral leishmanisis: a review of current treatment practices. Expert Opin Pharmacother 2002; 3: 1101-8.

61. Costa CHN, Pereira HF, Araújo MV. Epidemia de leishmaniose visceral no estado do Piauí, Brasil., 1980-1986. Rev Saúde Pública 1990; 24: 361-72.

62. Ministério da Saúde.Fundação Nacional de Saúde.Centro Nacional de Epidemiologia. Leishmaniose Visceral no Brasil: situação atual, principais aspectos epidemiológicos, clínicos e medidas de controle. Boletim Epidemiológico 2001; 6: 1-11.

63. Ministério da Saúde, Portaria GM/MS No. 2.472 de 31 de agosto de 2010.

64. Cabrera MAA, Paula AA, Camacho LAB, Marzochi MCA, Xavier SC, Silva AV et al. Canine visceral leishmaniasis in Barra de Guaratiba, Rio de Janeiro, Brazil: assessment of risck factors. Rev Inst Trop S Paulo 2003; 45: 79-83.

65. Costa CHN, Vieira JBF. Mudanças no controle de leishmaniose visceral no Brasil. Rev Soc Bras Med Trop 2001; 34: 223-8.

66. Shaw JJ. The relationship of sand fly ecology to the transmission of leishmaniasis in South America with particular reference to Brazil. In: Burger J. Contributions to the knowledge of Diptera. Vol. 14. Gainsville, Florida: Associated Publishers; 1999. p. 503-17.

67. Guerin PJ, Olliaro $P$, Sundar $S$, Boelaert $M$, Croft $S L$, Desjeux $P$ et al. Visceral leishmaniasis: current status of control, diagnosis and treatment and a proposed research and development agenda. Lancet Infect Dis 2002; 2: 494-501.

68 . Killick-Kendrick R, Killick-Kendrick M, Focheux C, Dereube J, Puch MP, Cadiergues C. Protection of dogs from bites of phlebotomines sandflies by deltamethrin collars for control of canine. Med Vet Entomol 1997; 11: 105-11.

69. Lachaud L, Chabbert E, Dubessay P, Reynes J, Lamothe J, bastien P. Comparison of various sample preparation methods for PCR diagnosis of visceral leishmaniasis using peripheral blood. J Clin Microbiol 2001; 39: 613-7.

70. Dunan S, Fromel D, Monjour L, Ogunkolade BW, Cruz A, Quilici M. Vaccination trial against canine visceral leishmaniasis. Parasite Immunol 1989; 11: 397-492.

71. Sacks LD, Belkaid Y, Mendez S, Kamhawi S, Seder R, Valenzuela J et al. Perspectives for new vaccines against leishmaniasis. In: Proceedings of the Second International Canine Leishmaniasis Forum; Sevilla, Spain; 2002. p. 31-7.

72. Borja-Cabrera GP, Correia Pontes NN, Da Silva VO, Paraguai de Souza E, Santos WR, Gomes EM et al. Long lasting protection against canine kala-azar using the FML-Quil-A saponin vaccine in an endemic area of Brazil (São Gonçalo do Amarante, RN). Vaccine 2002; 20: 3277-84. 
NALEVAIKO, P.C. et al. Leishmaniose no Brasil - Importância e perspectivas. PUBVET, Londrina, V. 5, N. 14, Ed. 161, Art. 1088, 2011.

73. Ministério da Saúde do Brasil. Secretaria de Vigilância em Saúde. Nota técnica sobre vacina anti-leishmaniose visceral canina. Brasília; 2004. 